\title{
Total Synthesis of (-)-Salviasperanol
}

\author{
George Majetich,* Ge Zou and Jeremy Grove \\ Department of Chemistry, University of Georgia, Athens, Georgia 30602 \\ majetich@chem.uga.edu \\ SUPPORTING INFORMATION
}

NMR SPECTRA FOR KEY INTERMEDIATES

Table of Contents ............................................ S5

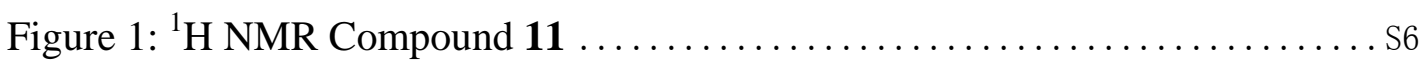

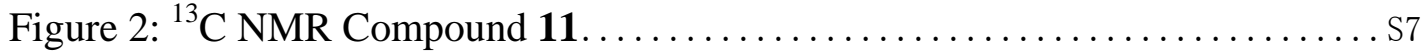

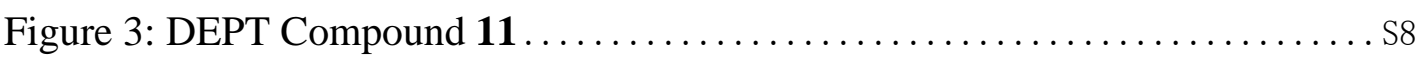

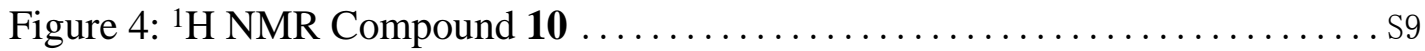

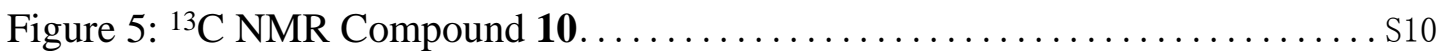

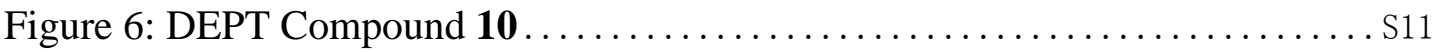

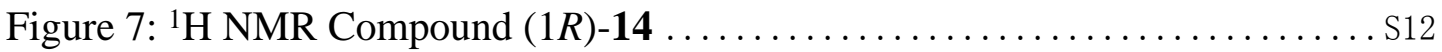

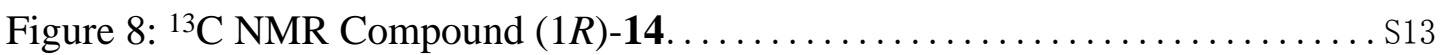

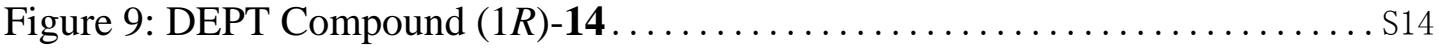

Figure 10: ${ }^{19}$ F NMR Mosher's Ester of Compound $(1 R)-14 \ldots \ldots \ldots \ldots \ldots \ldots$. . . . . 15

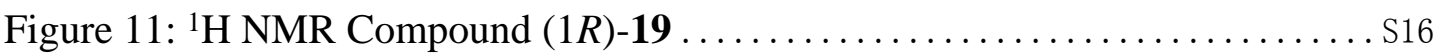

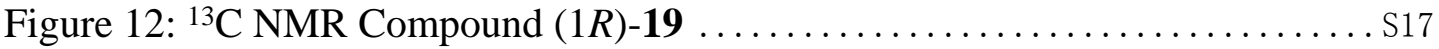

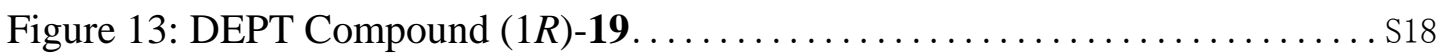

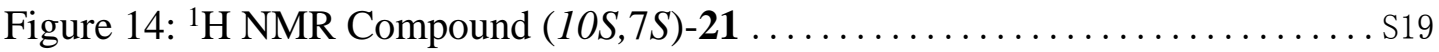

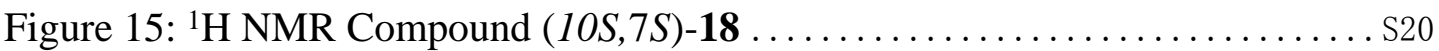

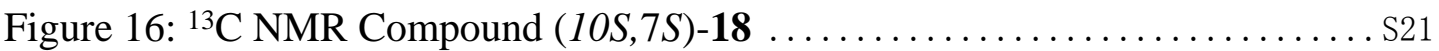

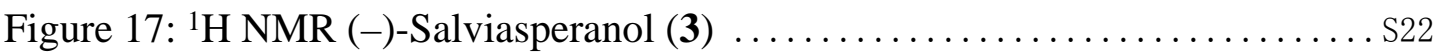

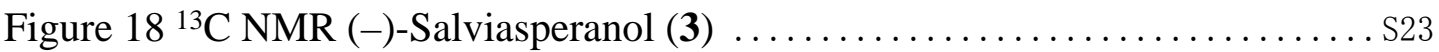




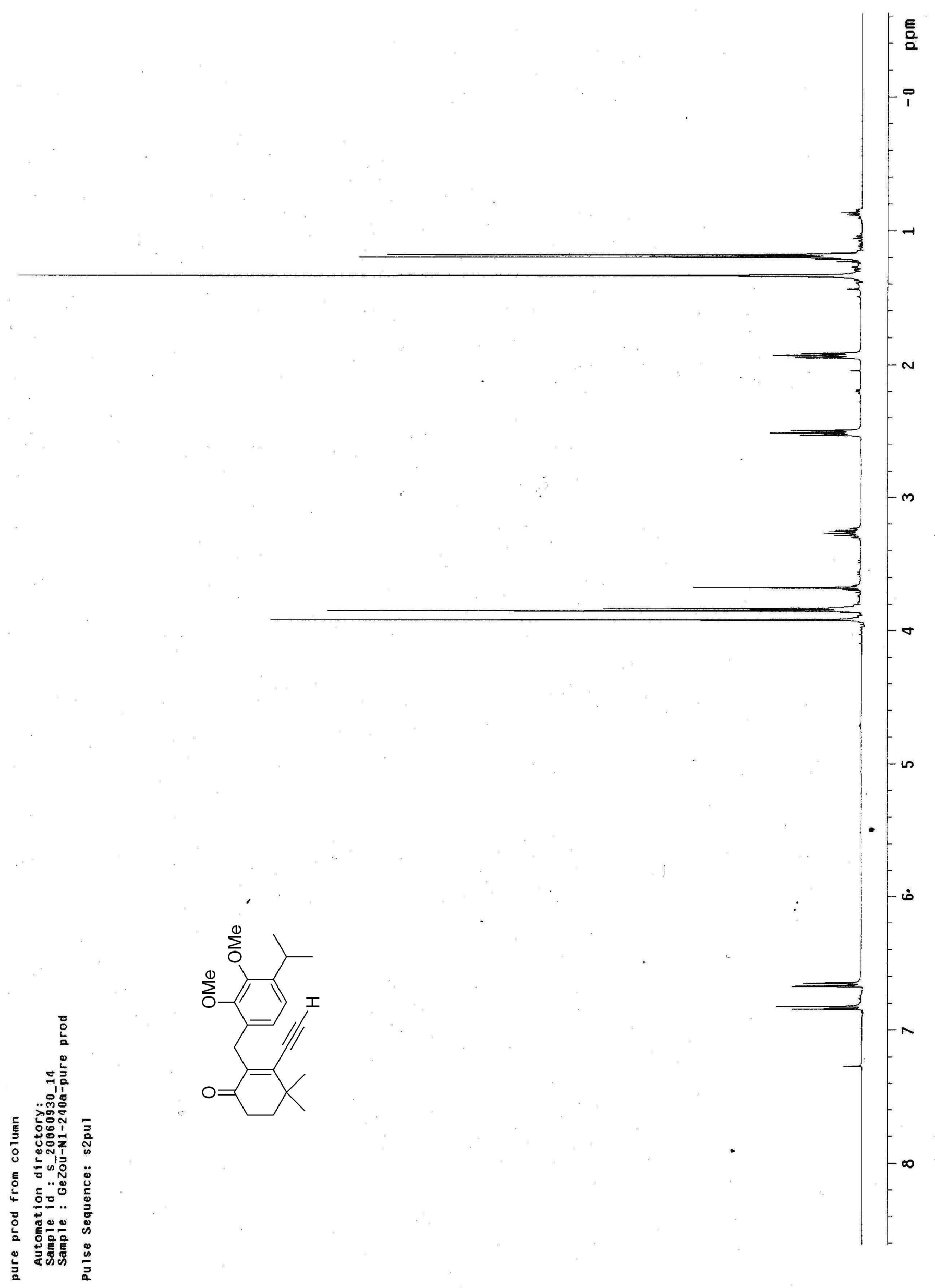

Figure $\quad 1:{ }^{1} \mathrm{H} \quad \mathrm{NMR}$

Compound 11 


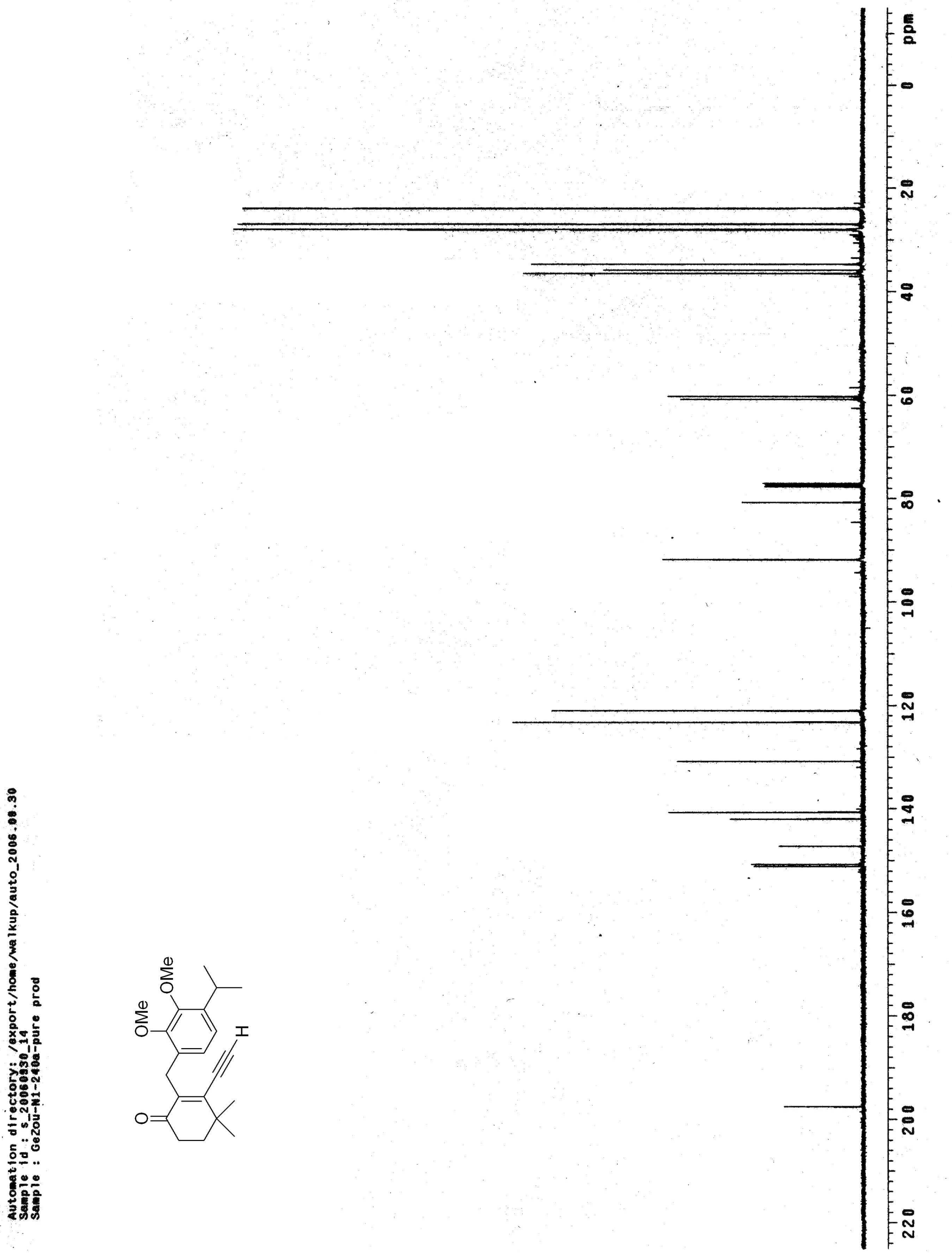

Figure 2: ${ }^{13} \mathrm{C} \quad \mathrm{NMR}$ Compound 11 


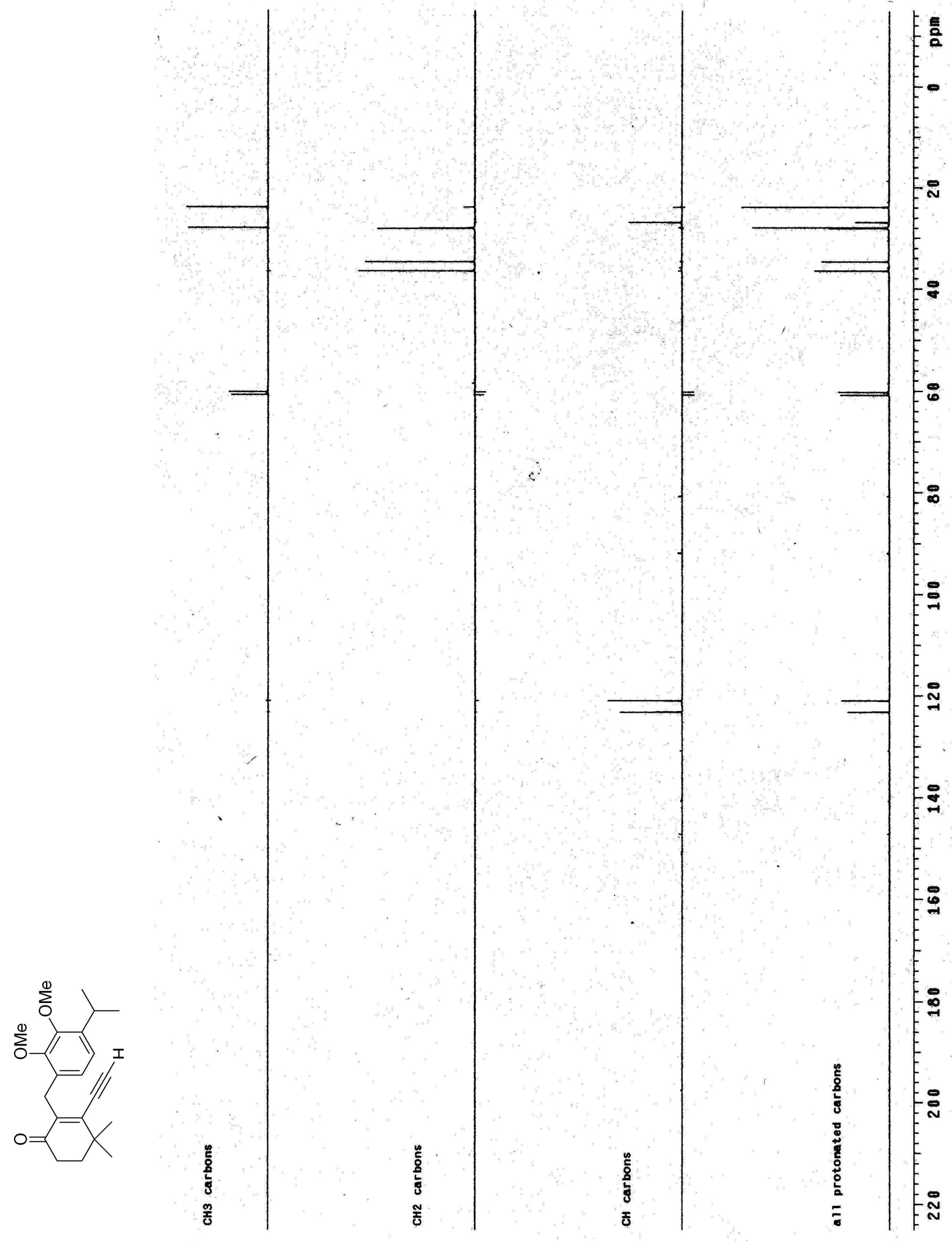

Figure 3: DEPT 


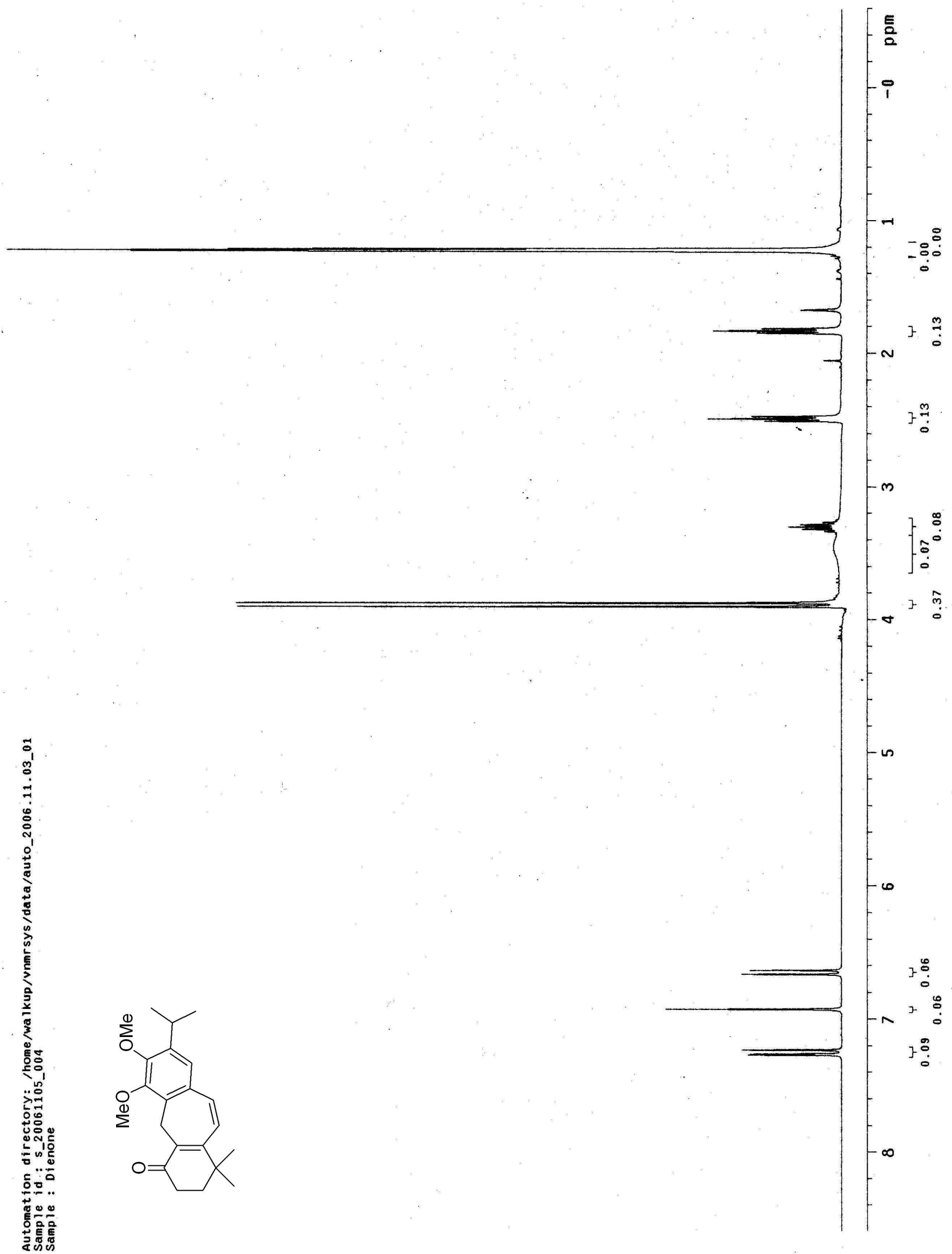

Figure 4: ${ }^{1} \mathrm{H} \quad$ NMR

Compound 10 


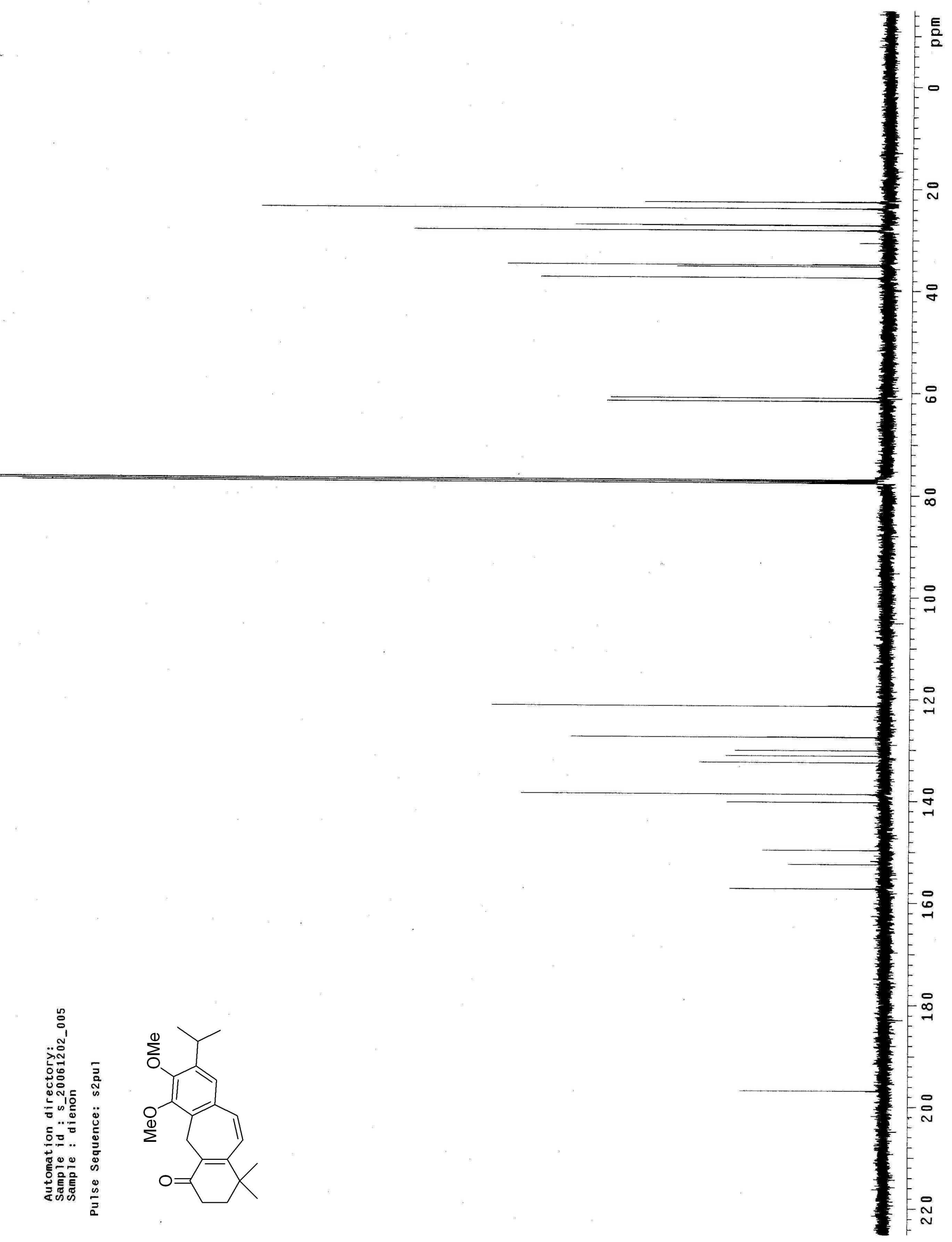

Figure 5: ${ }^{13} \mathrm{C} \quad \mathrm{NMR}$

Compound 10 

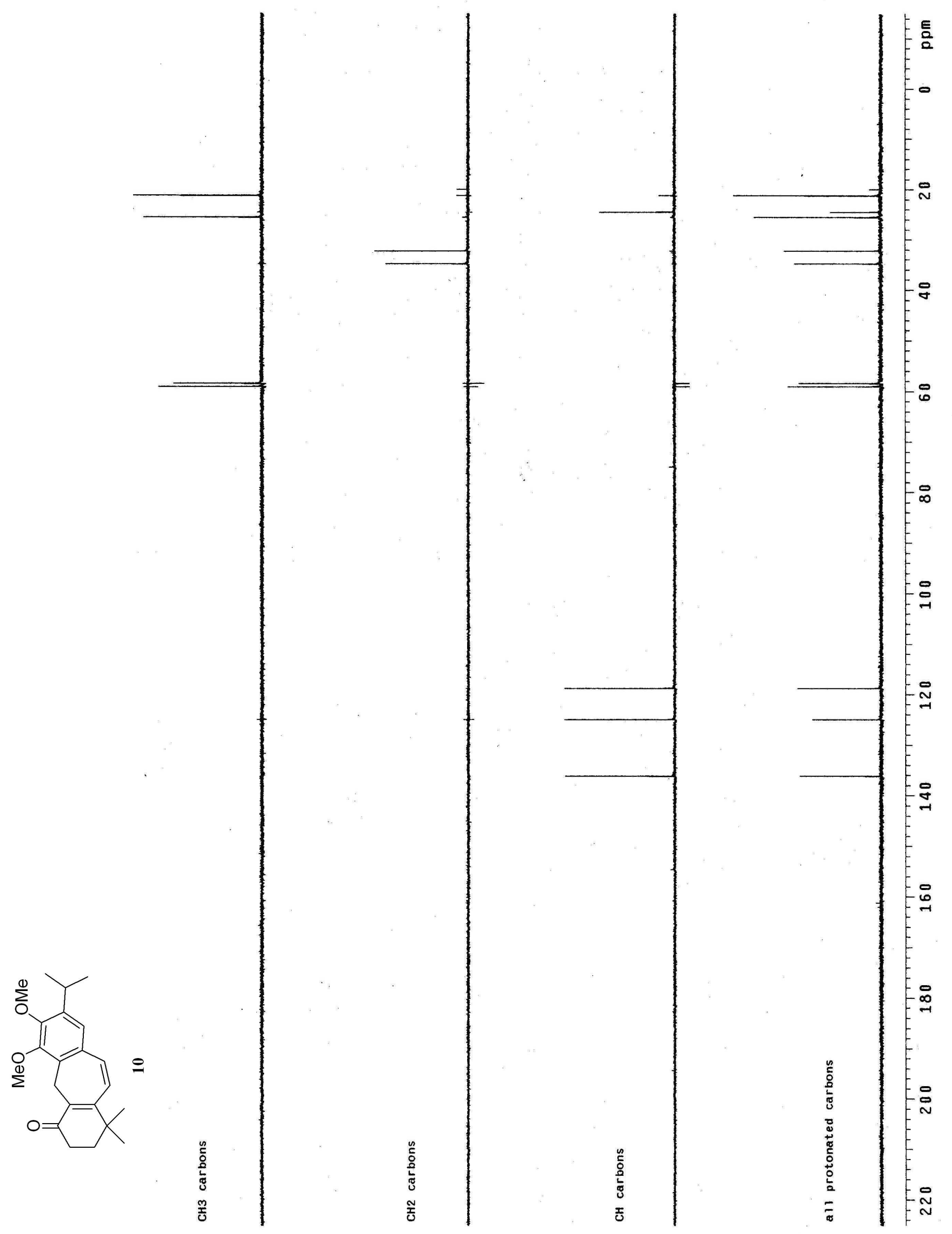

Figure 6: DEPT 


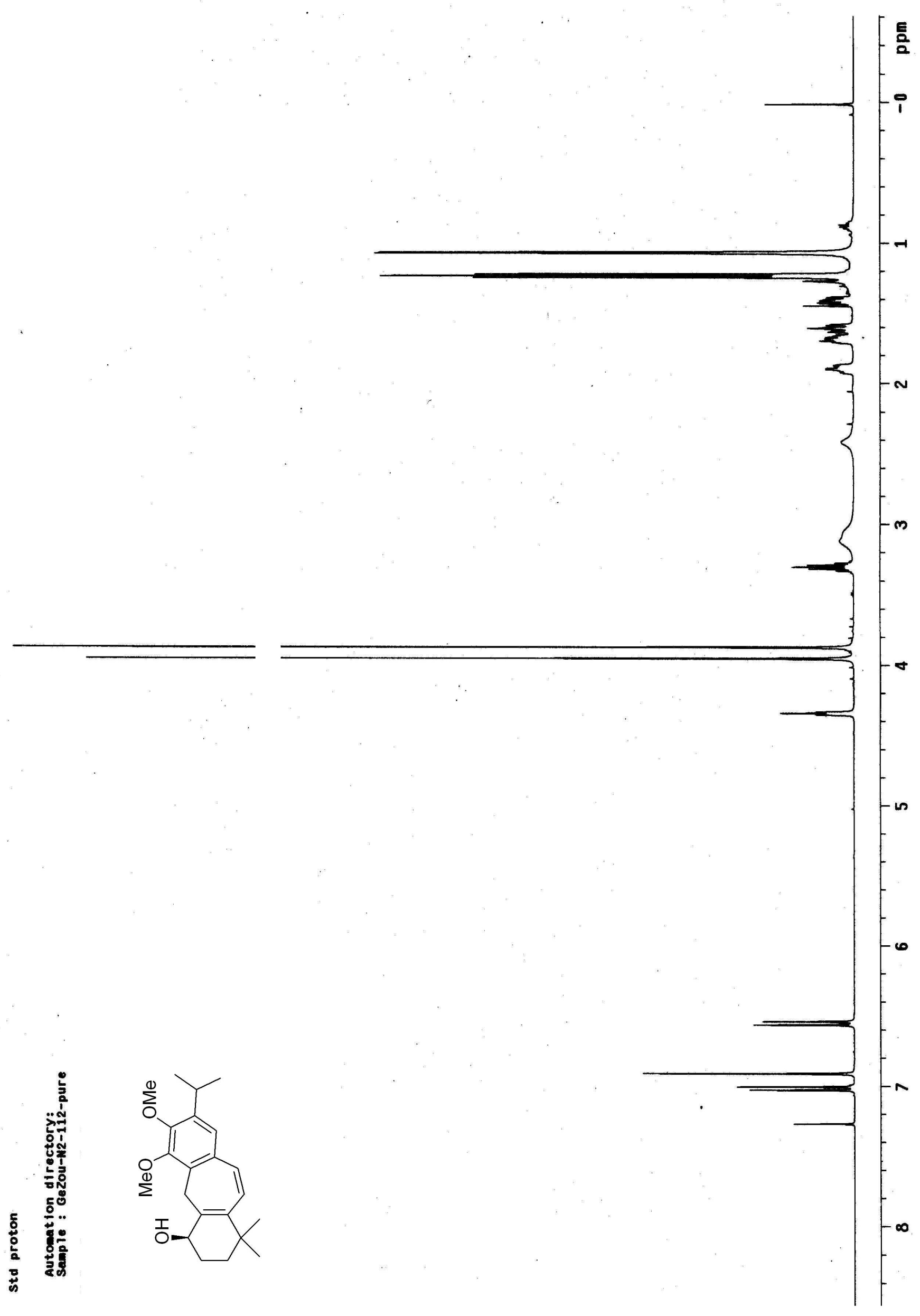

Figure $\quad 7: \quad{ }^{1} \mathrm{H} \quad \mathrm{NMR}$

Compound (1R)-14 


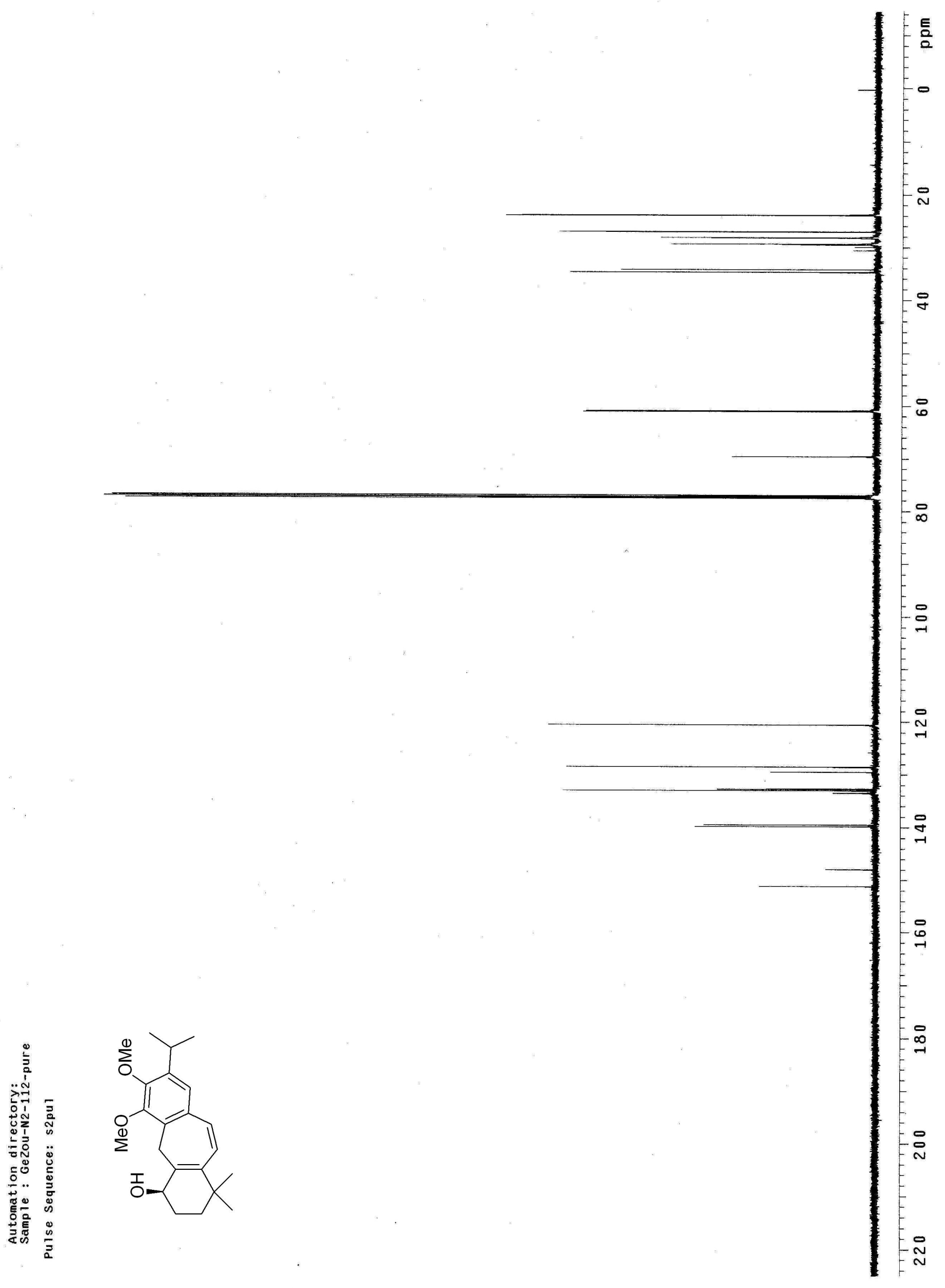

Figure 8: ${ }^{13} \mathrm{C} \quad \mathrm{NMR}$

Compound (1R)-14 

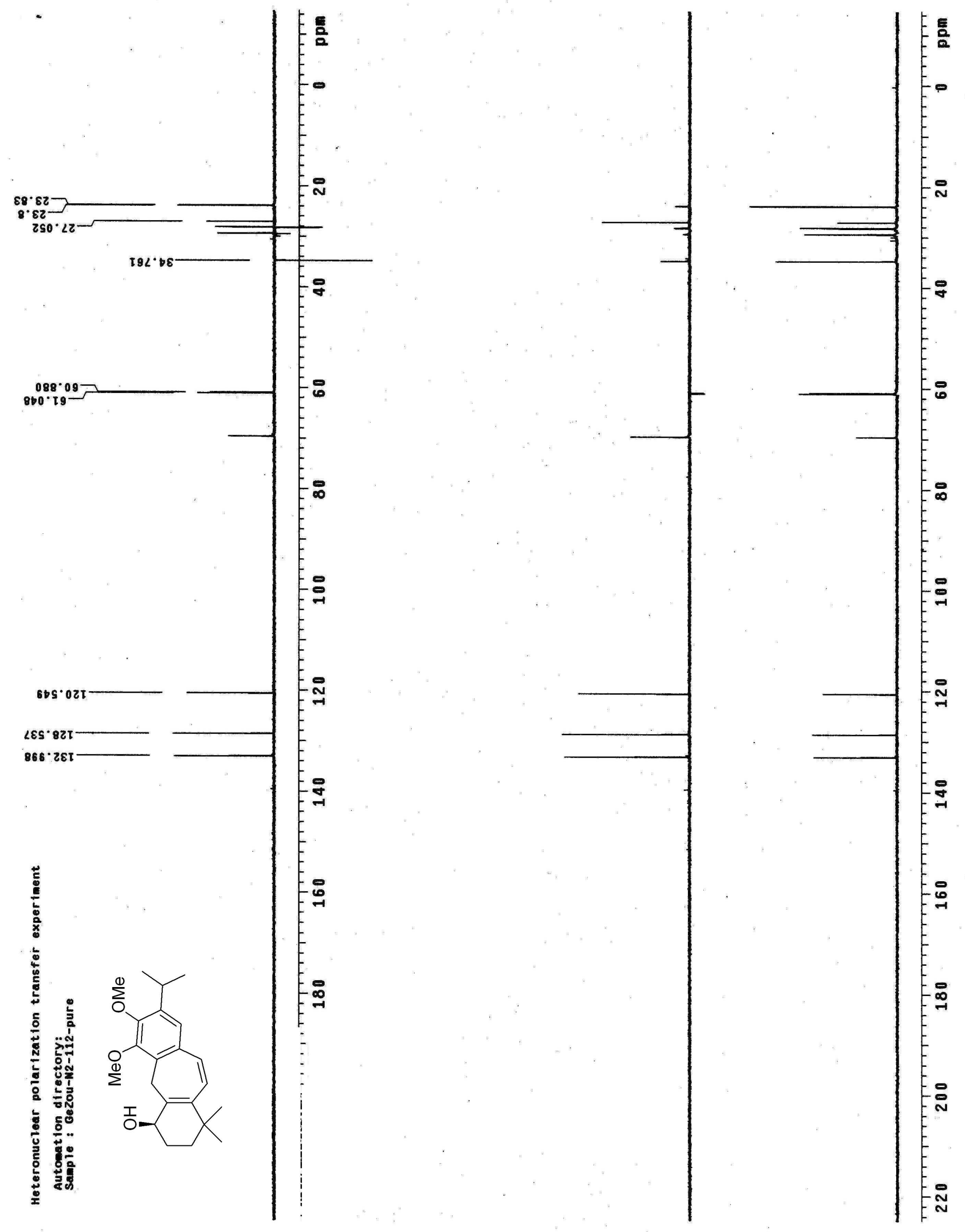

Figure 9: DEPT 


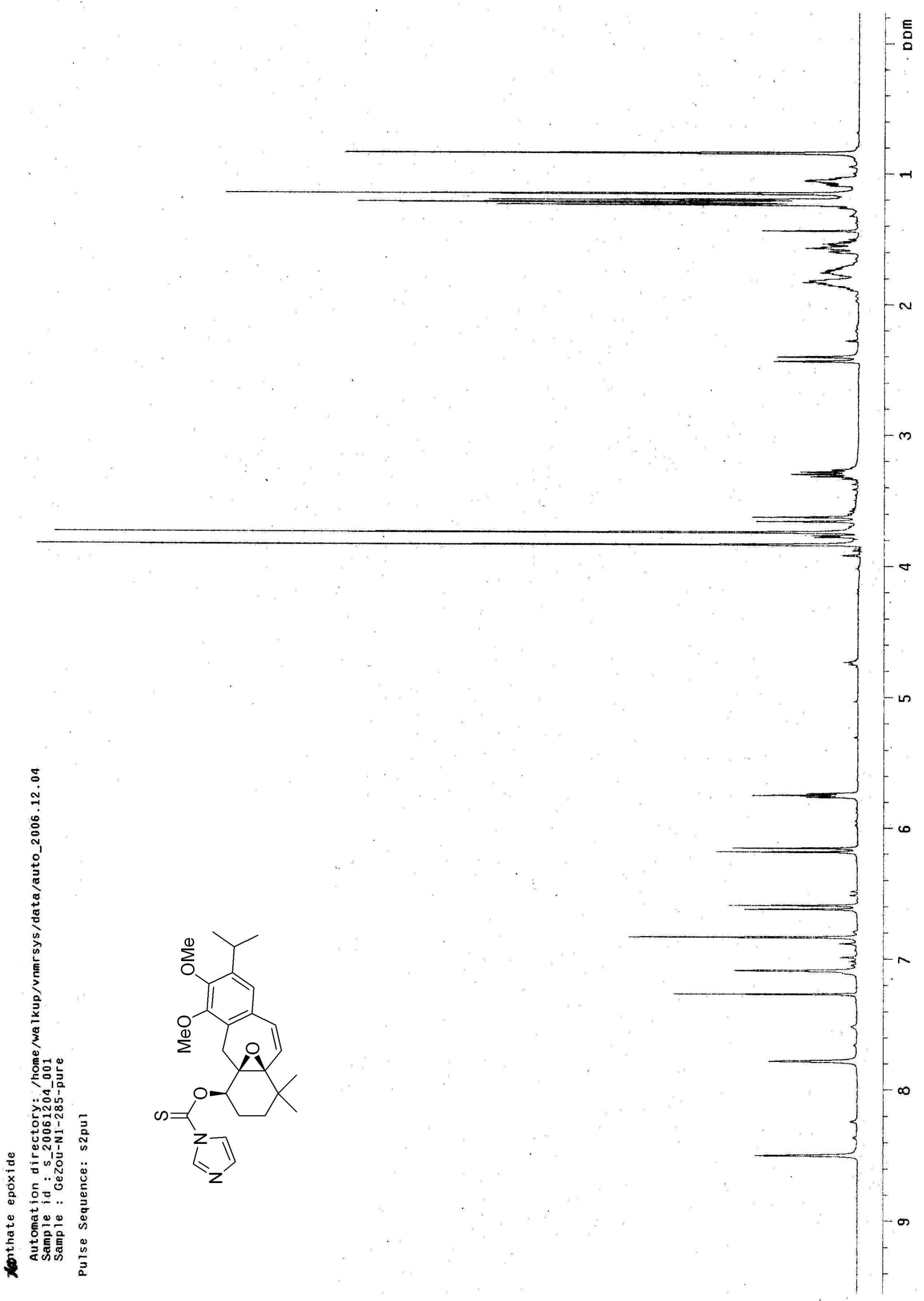

Figure 11: ${ }^{1} \mathrm{H} \quad$ NMR

Compound (1R)-19 


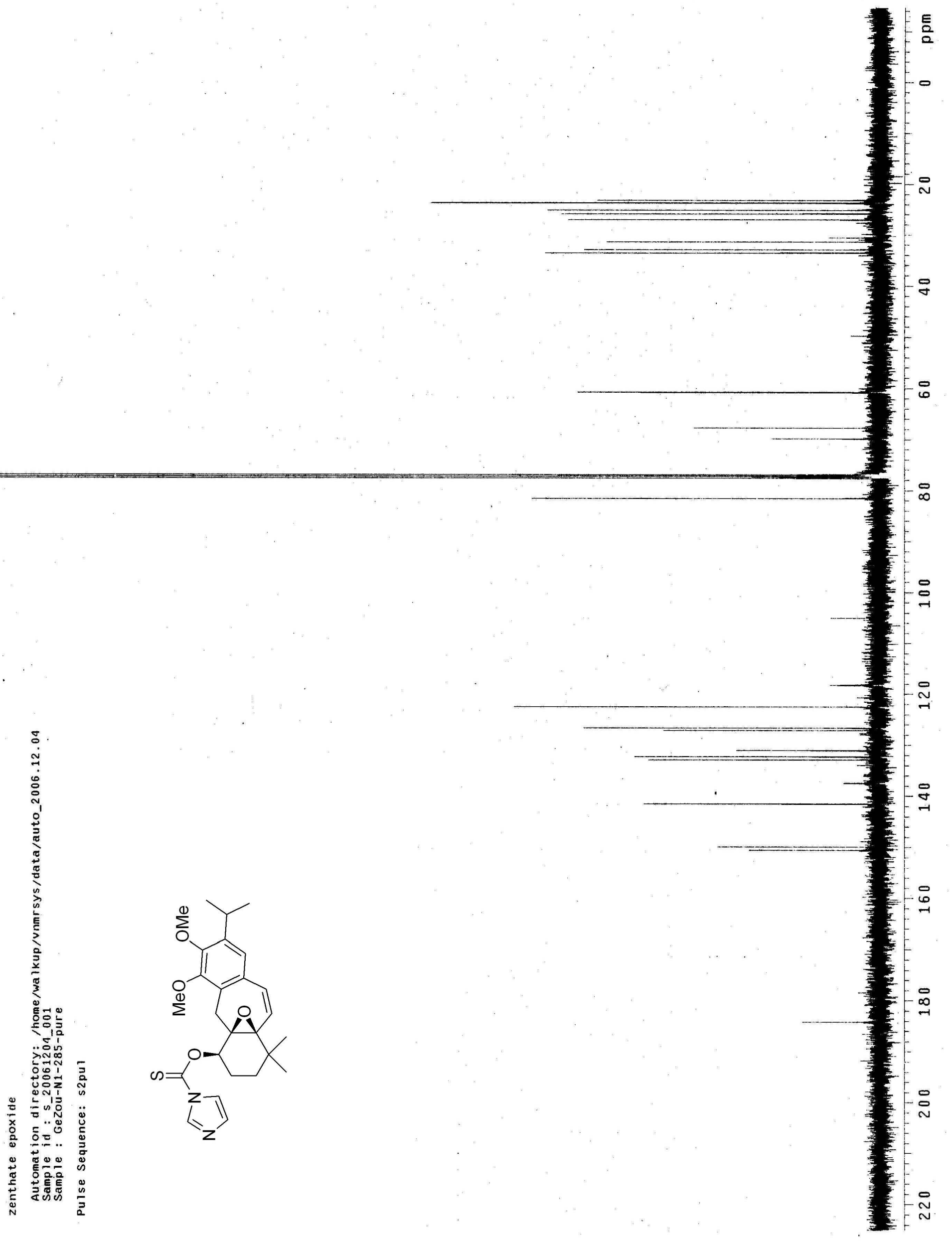

Figure 12: ${ }^{13} \mathrm{C} \quad \mathrm{NMR}$

Compound (1R)-19 

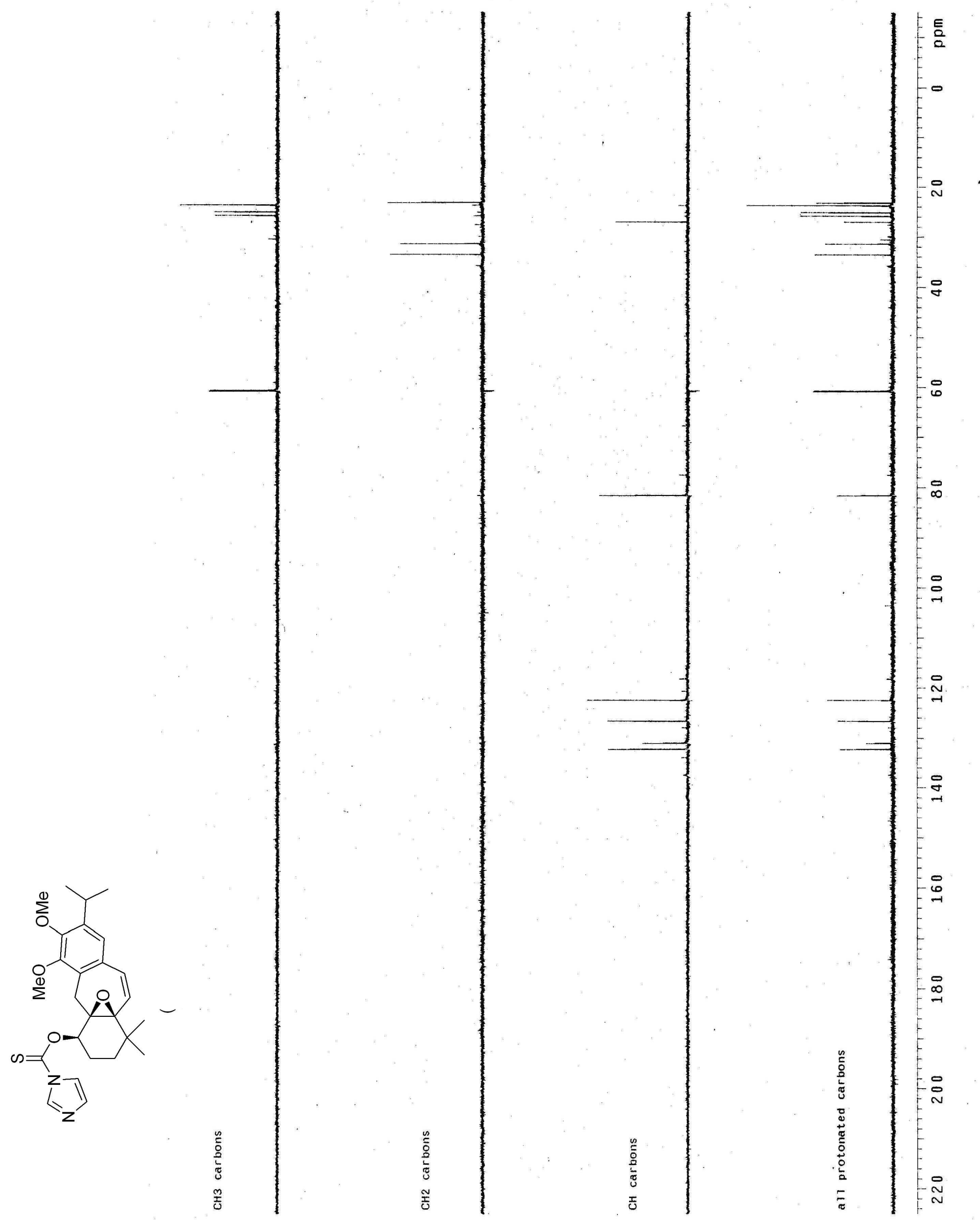

$$
\begin{aligned}
& \text { Figure 13: DEPT } \\
& \text { Compound }(1 R)-\mathbf{1 9}
\end{aligned}
$$

S18 


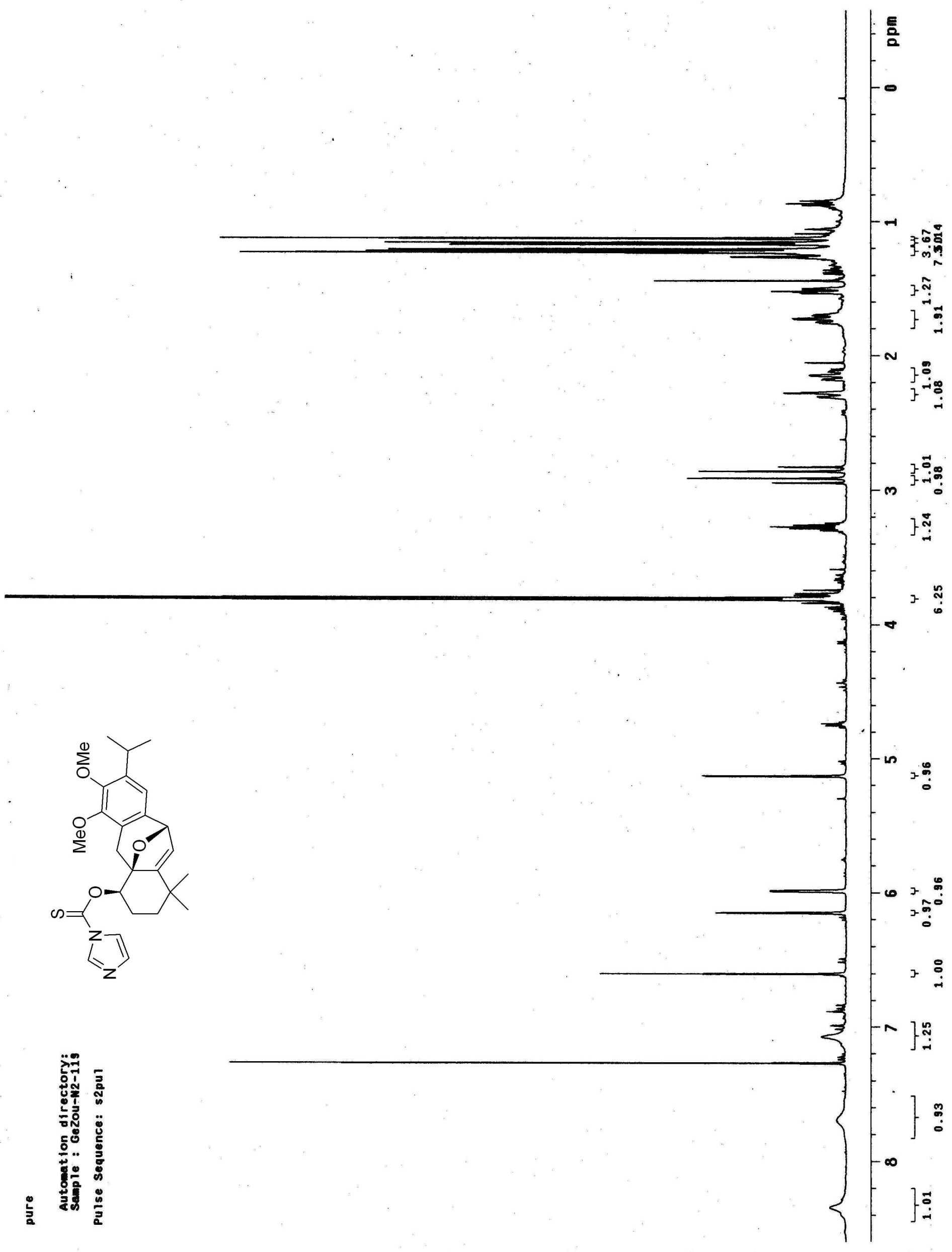




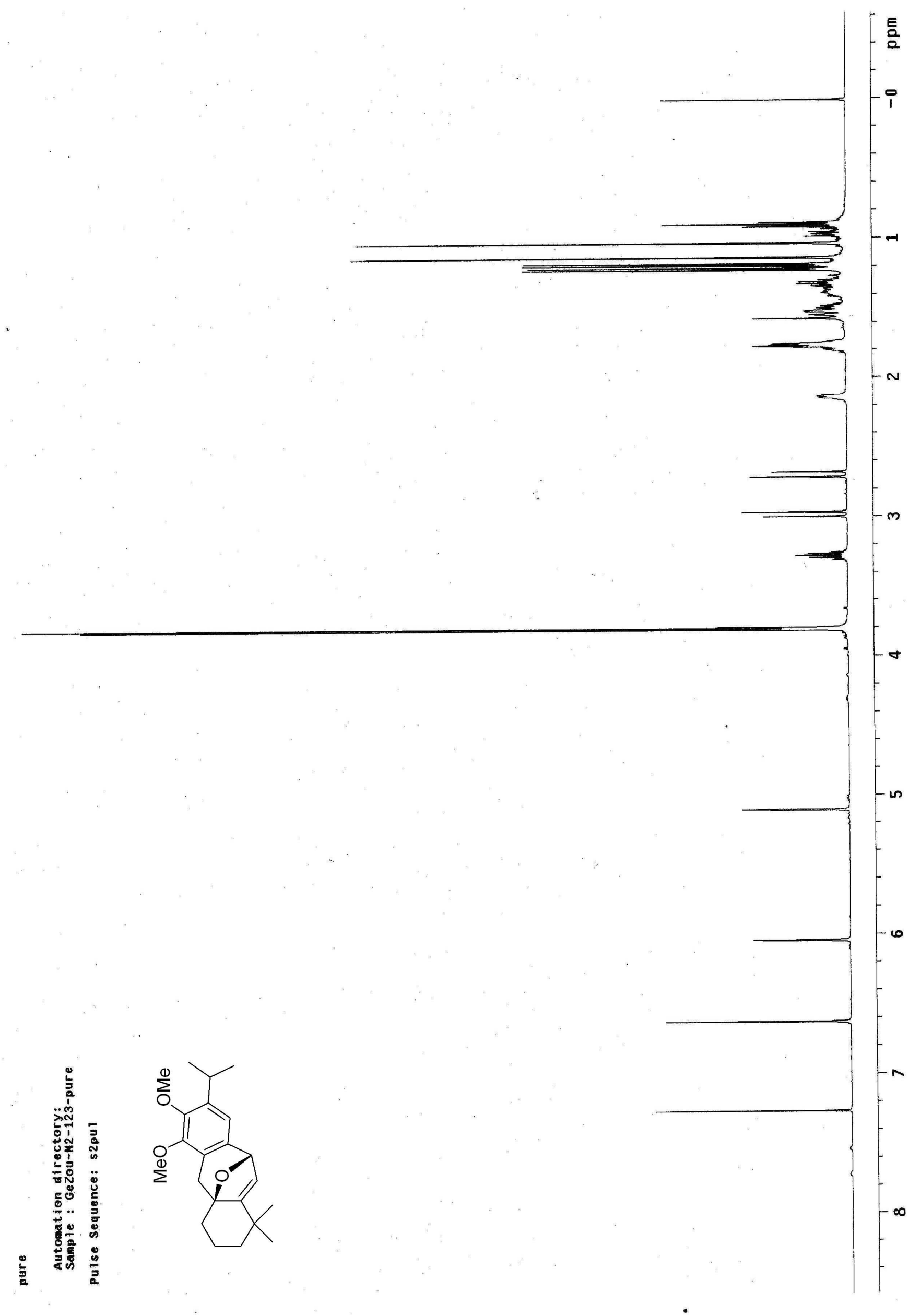

Figure 15: ${ }^{1} \mathrm{H} \quad$ NMR

Compound (10S, 7S)-18 


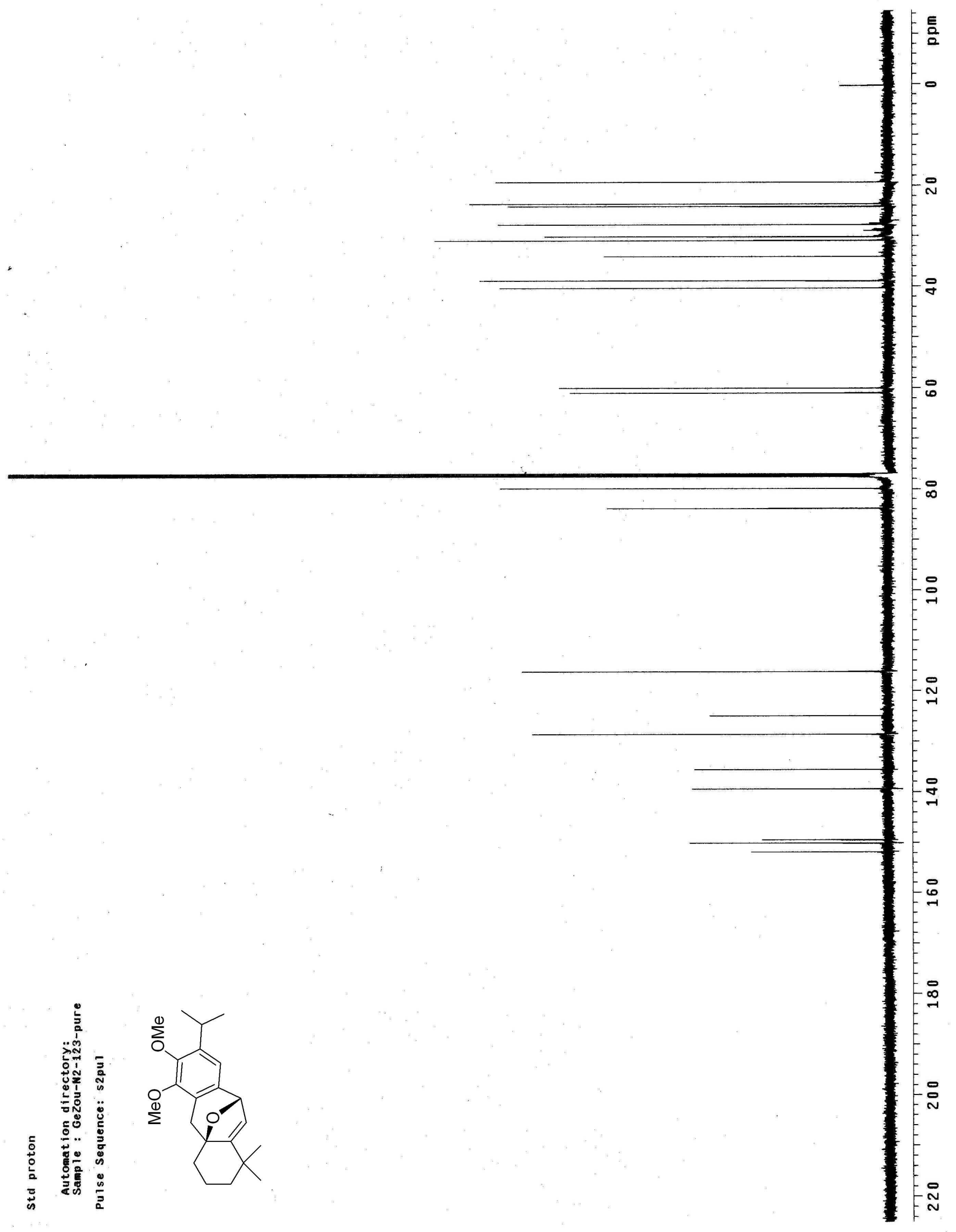

Figure 16: ${ }^{13} \mathrm{C} \quad \mathrm{NMR}$

Compound (10S, 7S)-18 


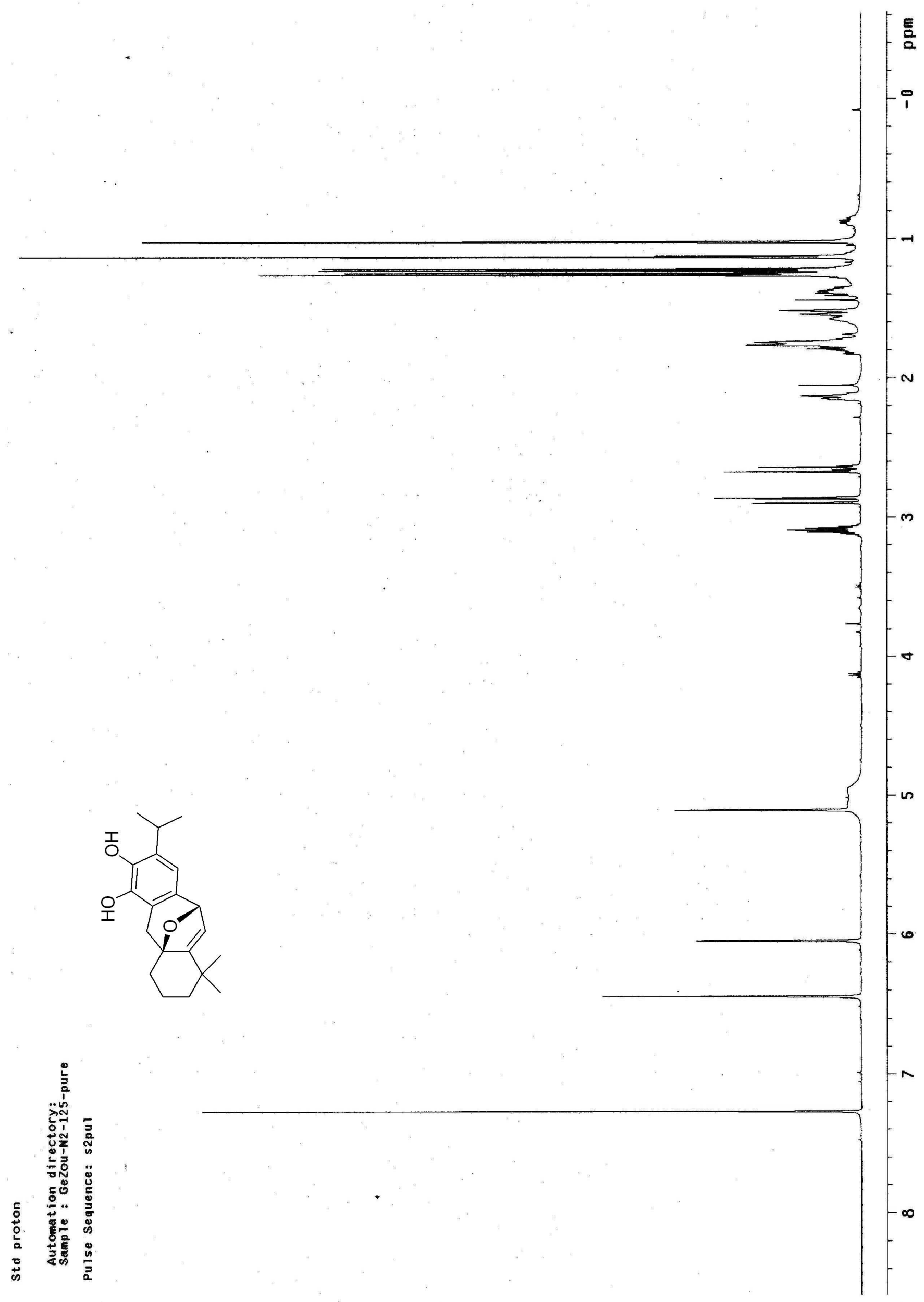

Figure 17: ${ }^{1} \mathrm{H}$ NMR

(-)-Salviasperanol 


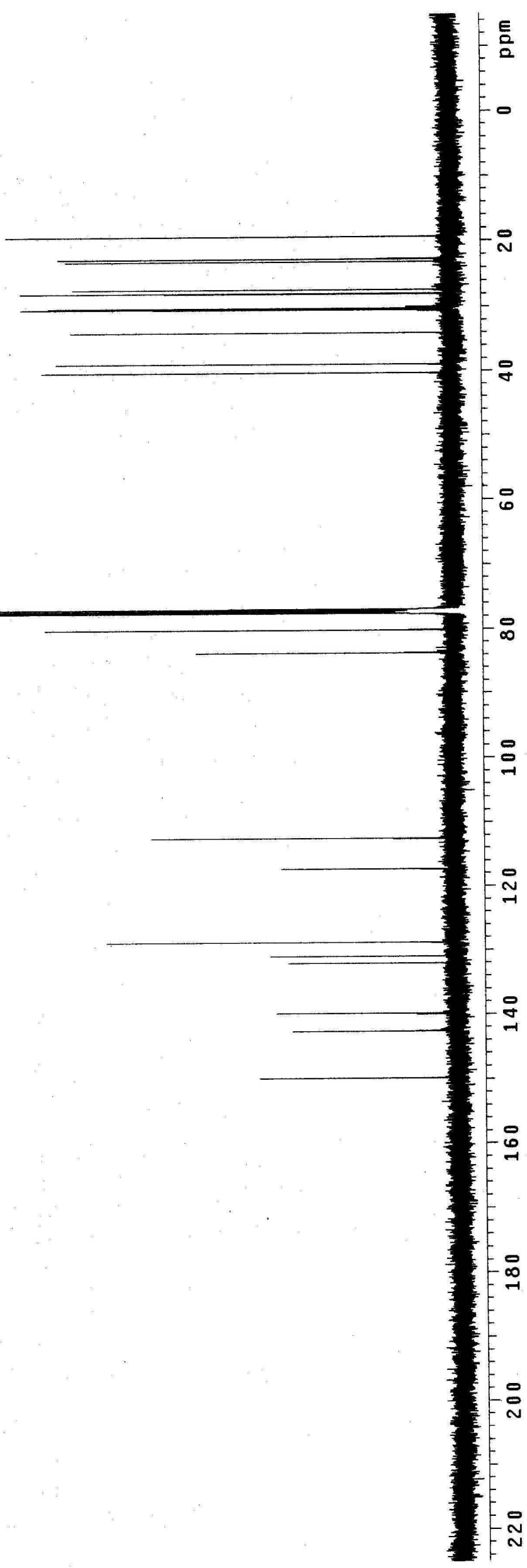

Figure $18{ }^{13} \mathrm{C}$ NMR

(-)-Salviasperanol (3) 